\title{
ON THE VALUE
}

or

\section{SYSTEMATIC EXAMINATION OF STILL- BORN CHILDREN.}

BY

JOHN BLAND SUTTON,

LECTURFR ON COMPARATIVE ANATOMY AND SENIOR DEMONGTRATOR OF ANATOMY, MIDDLESRX HOSPITAL MEDICAL COLLEGE.

Received February 22nd-Read March 11th, 1884.

For some considerable time it has been my custom to obtain, for purposes of anatomical and pathological inquiries, all stillborn children coming to hand in connection with the maternity department of the hospital. The object of this paper is to show that much valuable information may be gained by the systematic examination of fœtuses, as illustrated by a few selected cases possessing more than an ordinary interest.

In Dr. Peacock's well-known work on 'Malformations, \&c., of the Human Heart,' 1858, at p. 114, the following sentence occurs :

"There is also conclusive proof, in some cases, that the valvular disease is congenital; for it has been found in infants which have died very shortly after birth and even in fœtuses which have never breathed; in other instances its intra-uterine origin may be fairly inferred from the precise 
similarity of the diseased changes to those which are clearly congenital."

Further on he writes: "Analogy would lead us to expect what clinical experience demonstrates,-that the fœtus in utero is liable to diseases precisely similar in their nature and results, to those which affect the child after birth, and there can be no doubt that both the periand endo-cardium are not unfrequently the seat of inflammation during fœetal life."

These paragraphs, selected from Dr. Peacock's work, are really reflexes from the writings of other eminent pathologists who have "gone before ;" they are given here as an embodiment of general opinion, but they require to be supported by actual facts.

In January last I received the body of a male fœtus born at the eighth month of intra-uterine life. It was well developed, but the skin presented the familiar gloss so characteristic of extreme anasarca. The belly was extremely distended. Not only was the subcutaneous tissue of the limbs, trunk, and scalp filled with fluid, but the peritoneal, pleural, and pericardial cavities were distended to the utmost by pale straw-coloured fluid.

All the viscera were duly and carefully looked to, but the only morbid conditions detected were large, soft, easily detached vegetations on the cusps of the valves guarding the aortic and pulmonary orifices, and a puckered condition of one of the curtains which form the mitral valve (Plate 1, figs. 1 and 2).

Here was a case of recent endocarditis, but from what cause arising? The mother had passed through several pregnancies in a satisfactory manner, had never suffered from rheumatic fever or any allied disease, and, as ascertained by two competent observers, the mother's heart was to all outward appearance and auscultatory tests perfectly normal. The husband and remaining children were in a healthy condition.

That several diseases may be transmitted from mother to child is beyond all disputation, e.g. syphilis; and the 
celebrated case recorded by Hunter, in the 'Philosophical Transactions,' for 1780, of a " Woman who had Smallpox during her Pregnancy, and who seems to have Communicated the same Disease to the Fœtus," is a case in point. Dr. Edward Jenner has recorded similar cases in Vol. $i$ of the Transactions of this Society.

In the fœetus, whose case I have recorded, no disease of the mother can be ascertained likely to cause endocarditis in her offspring, hence we are driven to the conclusion that a foetus may contract a disease independently of its mother! In Dr. Jenner's case just mentioned it seems probable that one of the fotuses contracted smallpox, whereas the mother escaped.

The case now to be related differs in its nature from the one just considered. It concerns the body of a female child which survived its birth three days, having been born at full time. Death was certified as being occasioned by "pneumonia."

On opening the abdomen the large size of the stomach attracted attention, and careful dissection disclosed the following state of affairs :

The stomach was three times larger than usual and presented a constriction at the ordinary situation of the pylorus. An inch farther on, the intestine which was very dilated, suddenly terminated in a cul-de-sac having no communication with the surrounding viscera, even by fibrous tissue (Woodcut, fig. 1, p. 166). Immediately below this, and in contact with the head of the pancreas, was the upper extremity of the small intestine with the common bile-duct entering it.

Thus the continuity of the alimentary canal had been broken at the midlle of the duodenum, directly above the entrance of the common bile-duct. Below this spot the intestines were normal and as usual contained meconium, but this was small in quantity. The stomach held two ounces of fluid, in which brandy could be detected. On inverting the stomach the line of muscular fibre forming the pylorus was easily distinguished (see P, in Fig. 2, p. 
166), and as represented in the figures is intended to give visual expression to this abnormal condition of things.

I am unable to advance any satisfactory explanation of this malformation, either on morphological grounds, or from anything known concerning the embryological history of the alimentary canal. It may bear some relation to the development of the liver, which commences as a diverticulum of the gut, for Dr. Wilks ${ }^{1}$ and Dr. George Buchanan ${ }^{2}$ have each recorded cases of partial obstruction of the intestine by a diaphragm at this point of the duodenum, above the papilla, which marks the entrance of the united ducts of the liver and pancreas. Mr. George Eastes $^{3}$ has also described a similar case in which the obstruction was complete.

Dr. Buchanan thinks it possible that the diaphragmlike structure encountered in his case resulted from the hypertrophy of one of the valvulæ conniventes. Mr. Pollock, in writing on congenital strictures of the small intestine, takes the same view, for in 'Holmes' System of Surgery,' 3rd edit., vol. ii, p. 712, in a foot-note we read :

"From the plate which accompanies the description given by Dr. Wilks, it would appear that the contraction in all probability arose from a highly developed valve of the intestine; in the centre of this valve or stricture may be seen a very small circular hole, apparently not larger than would admit a probe."

My object in reporting this case and making these references is to show that this view is absolutely untenable. After very many observations particularly directed to this question and to the date of the appearance of the valvulæ conniventes, it may be clearly demonstrated that these folds of the mucous membrane do not arise until two or three weeks before birth. I have never seen them before birth, but Mr. Shattock has found them quite rudimentary in the lower part of the duodenum and upper part of jejunum, in a well-developed fotus at full term. If these observations be confirmed by independent workers, then 1 'Trans. Pathol. Soc.,' xii, p. 101. ' 2 Ib., xii, p. 121. ' Ib., xxxi, p. 114. 
the hypothesis, which would regard these abnormalities as examples of hypertrophied valvulæ, no longer holds its ground.

The third fœtus presents features of interest to those concerned with surgical pathology.

The drawings represent the spinal column, thorax, and rudiments of the upper limbs of a full term female fœtus (Plate I, fig. 5 ; Plate II, figs. 1 and 2).

The noteworthy points in the external conformation of the body are represented in Plate I, fig. 5. The upper limbs merely consist of a finger attached to each shoulder. On dissection, the clavicle is normal, the scapula wellshapen and of normal size, but in place of a glenoid fossa it presents a rounded head of hyaline cartilage. To this succeeds a cartilaginous - representative of the semilunar bone, followed by an os magnum also in cartilage; articulating with this is a metacarpal bone, supporting in its turn three phalanges. Humerus, radius, and ulna are not represented.

The spinal column presents a considerable curvature, involving the whole column, the concavity of the curve looking to the left. The unnatural bend commences about the third lumbar, and extends, increasing in sererity, to the mid dorsal region; it then ascends to the neck region, ending about the second or third cervical vertebra. The bones composing the column are normal in number, but the centra are narrower on the concave than on the convex side of the curve. The thorax has the usual deformation seen in lateral curvature; for example, the chest is deeper and the intercostal spaces are wider on the convex than on the concave side of the curve, exactly as one sees it in instances of the disease occurring in children.

There are several cases on record of congenital lateral curvature, but in all these cases the curves result from the interpolation of segments or half vertebræ; thus in a case Rokitansky records in his 'Pathological Anatomy,' vol. iii, p. 230, there were four half vertebræ, with their VOL. LIXII. 
half arches and processes, too many. They were so placed on the two sides as to compensate one another, and cause four curves in the spine; two in the dorsal, one in the dorso-lumbar region, and the fourth involved the sacrum. But in the case described by me no such condition can be detected.

In connection with this case it will be well to mention that the Middlesex Hospital Museum contrins a well-prepared skeleton of a presumably full-grown female, in which there is a lateral curvature of the spine involving the lumbar region with a second curve in the dorsal portion of the column. In this skeleton eleven vertebral bodies exist in the dorsal series, but there is the normal number of spinous processes, so that the curve in the dorsal region results from the deficiency of a portion of a vertebral centrum, and as there is no evidence to lead one to suppose the defect to be due to disease, it must, therefore, be regarded as a congenital defect. This is not all, for in this self-same skeleton the right thumb bones are exceedingly small and dwarfed with defect in the number of the carpal bones, and on the left side the radius is absent and so is the thumb, whilst the ulna exists as a short and exceedingly curved bone.

One question intrudes itself on the mind engaged in meditation on this adult skeleton and the fœetus represented on Plate II, fig. 1.

Does any relation exist between congenital curvature of the spine and defective development of the upper $\operatorname{limb}$ ?

This question suggests another, Are the two conditions so frequently associated as spina bifida and club-foot?

The query cannot be answered until more observations have been recorded.

The remaining cases of interest will be treated briefly. Three fœtuses presented abnormal conditions of the kidneys.

The first was an example of single kidney, the left one being completely wanting, no trace of ureter, or anything 
to represent the renal artery or vein of that side. The right kidney was twice the usual size, and the ureter was very large and dilated. The urethra and bladder were normal.

The remaining two were examples of cystic kidney, not hydronephrotic, due to interference with the outflow of urine from ureter or urethra; but the kidneys were enlarged and made up of a congeries of small cysts, the largest of about the size of a pea. The ureters, bladder, and urethra were normal. In one of these specimens the kidney was of the "horseshoe" variety. In the other specimen, the kidneys were of the usual shape, but presented an interesting condition in relation to the left testis. The occurrence of intra-uterine peritonitis has long been recngnised as one cause of retained testicle; in this specimen the right testicle was in its normal situation, but the left one was firmly attached by fibrous tissue to the lower end of the corresponding kidney, the inguinal canal was patent, and the funicular pouch of peritoneum occupied the scrotum. The matting together of coils of the intestines and the thickened condition of the peritoneum spoke plainly of peritonitis.

Deficiency of the diaphragm.-When we reflect that one of the chief characteristics of mammalian myology is the diaphragm, anything concerning its defective development must be of interest. Many cases of partial deficiency of this muscular septum are recorded; to these I add another. The fotus was born at full term, and on examining it I found that the left lobe of the liver filled up the corresponding side of the thorax, it having passed through a hole caused by the defective development of the diaphragm. The only representative of the left lung was a small piece of pulmonary tissue an inch square. The remaining viscera were normal.

Cleft palate was seen in three instances, one of which was associated with a rare defect in the sphenoid bone, viz. absence of the floor of the pituitary fossa. This is important in its bearing on the occasional occurrence of 
meningocele, bulging into the upper part of the pharynx and nasal fossa. That such a defect should occur in this situation may be readily comprehended, seeing that the fossa in question marks the spot where the trabeculø cranii separate to enclose the pituitary body.

Meningo-encephalocele occurring in the occipital region was seen once, and this leads me to offer a few remarks on a neglected point in the anatomy of this part of the skull which has some bearing on meningocele in this situation.

If the skull of a human fœetus be examined about the third month of intra-uterine life, the foramen magnum will be found formed in the following manner : In front is the cartilaginous basi-occipital with its nucleus just appearing; on either side are the ex-occipitals, with their centres visible in the mass of cartilages forming the greater portion of the side-walls of the skull ; and posterior to these is a membranous space. These relations of parts may be seen on reference to Plate I, fig. 4. This space or fontanelle extends upwards to the situation of the occipital protuberance, and during early development serves to separate the two inferior centres of this portion of the bone, for the squamo-occipital arises from four centres, the two upper ones originating in membrane, and the two lower ones in cartilage, the four pieces eventually becoming confluent at the situation of the protuberance. This membranous space, which I propose to term the "temporary occipital fontanelle," is really a remnant of the original membranous roof of the cranium. During the fourth month, the two inferior centres of the squamooccipital fuse together and send down a bony spiculum to occupy the fontanelle, as see in Plate I, fig 3. Kölliker figures this spicule of bone in his 'Entwicklungsgeschichte,' $1876-79$, p. 450 , fig. 278 , but the membranous space has evidently escaped his observation. By the commencement of the fifth month, the fontanelle has become filled and the foramen magnum is bounded as usual by the squamooccipital. From these statements it is obvious that from 
the beginning of the third to the end of the fourth month of intra-uterine life, there exists a fontanelle extending from the foramen magnum, and when at its greatest relative size reaching into the occipital protuberance. The practical bearing of the case is this: in all probability it is this membranous space or temporary weak spot in the cranium that explains the frequent occurrence of meningocele and encephalocele in this situation.

It would prolong this paper indefinitely to describe all the cases of interest which have come under my notice during the past two years. I have contented myself by giving the details of those which seemed, on account of their rarity and scientific bearing, to be of interest to the physician and surgeon.

Concerning the diseases of the fœtus we know but little. Malformations of the heart and fœtal abnormalities in general have received a "lion's share" of attention. I feel that much good light may be shed concerning hereditary diseases if the bodies of stillborn children be as systematically examined in our hospitals, as are the patients who pay the "debt of nature" in these institutions. 


$$
B_{2}
$$


FIG. 1.-Complete stricture of the duodenum immediately above the papilla for the united bile and pancreatic duct. P. Pylorus. G.B. Gall bladder. D. Duodenum.

FrG. 2.-The cul-de-sac inverted, showing a band of muscular fibres, (P) belonging to the sphincter. (Size of nature.) From drawings by Mr. Osmond. 


\section{DESCRIPTION OF PLATES I AND II.}

On the Value of Systematic Examination of Stillborn Children. (John Bland Sutton.)

\section{Piate I.}

FIG. 1.-The pulmonary orifice of the heart of a foetus, showing recent vegetations adherent to the valves. ( $\frac{2}{1}$ the size of nature.)

Fir. 2.-The left ventricle of the same heart opened, to show recent vegetations on the cusps of the aortic valve and the puckered condition of one curtain of the mitral valve. $\left(\times \frac{2}{1}.\right)$

FIG. 3.-Posterior view of the skull of a human foetus at the end of the fourth month. It is intended to show the "spicule" of bone extending into the membrane of the "temporary fontanelle." Other letters as before. s. The spiculum. (Twice the size of nature.) Semi-diagrammatic.

Fig. 4.-Posterior view of the skull of a human fœtus at the third month, to show the temporary occipital fontanelle, w. 8.o. Squamooccipital. M. Foramen magnum. E.o. Ex-occipital. B. Basioccipital. c. Chondro-cranium.

Fig. 5.-The external configuration of the fœtus, of which Figures 1 and 2 on Plate II represent the skeleton.

From drawings by Mr. Wynter.

\section{Plate Il.}

Fig. 1.-A drawing to illustrate a case of ateral curvature of the spine in a human foetus.

Fig. 2.-The skeleton of the dwarfed limb from the same case. s. Semilunar. M. Magnum. M.c. Metacarpal bone. 1, 2, 3. The phalanges. (Natural size.)

From drawings by Mr. Osmond. 


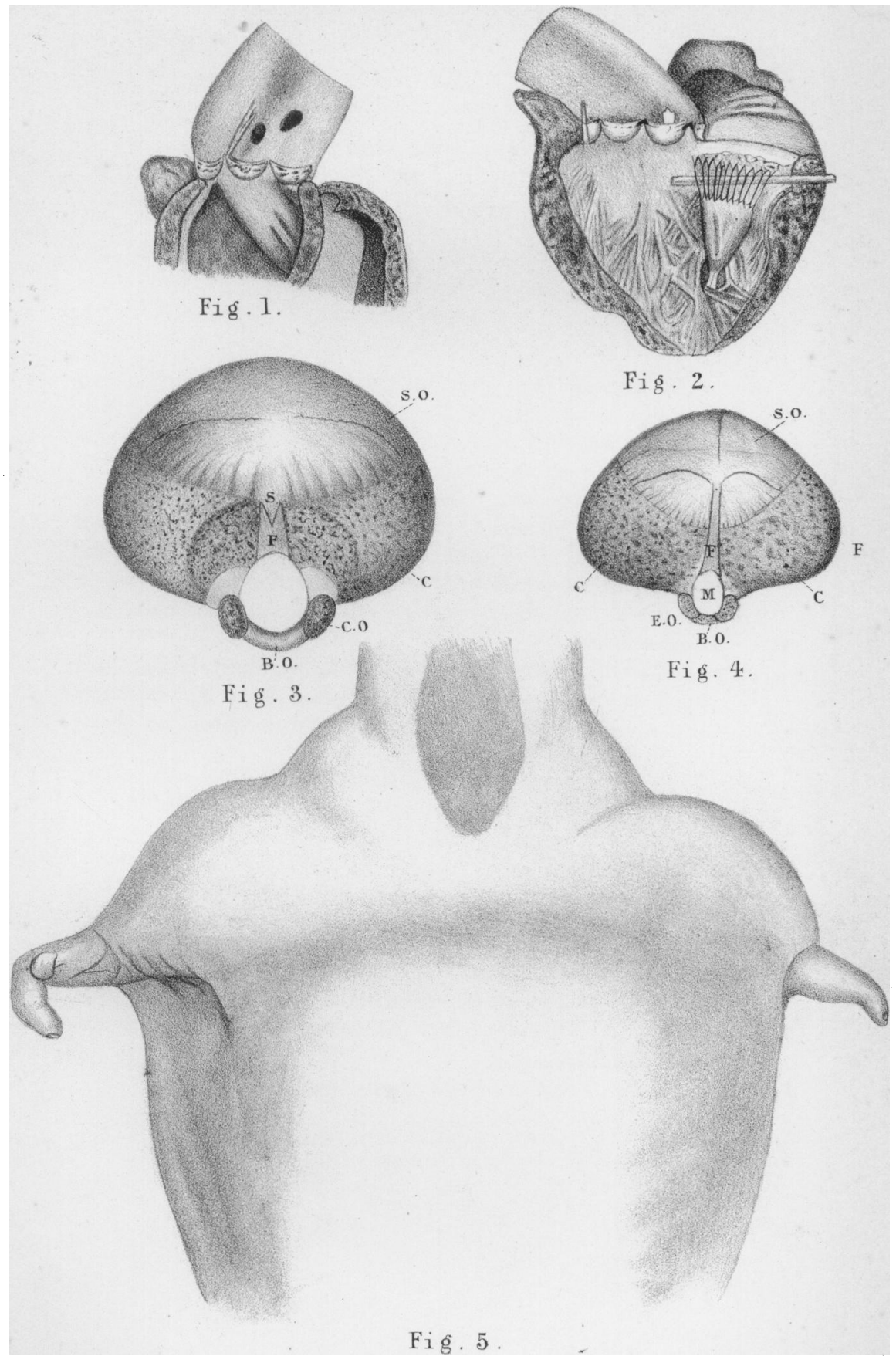


Plèté.II.

Med. Chir, Trans. Vol. LXVI.

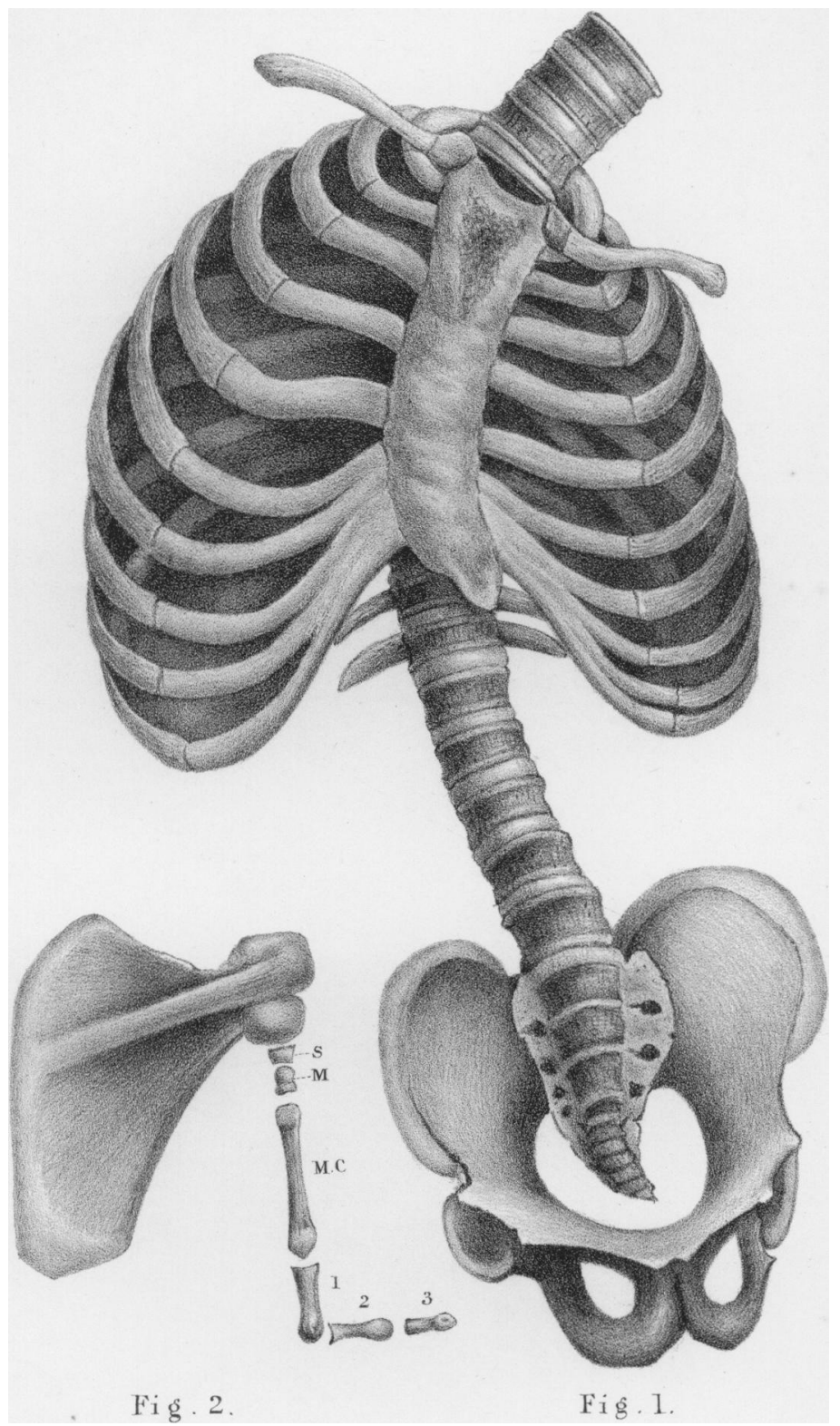

Mintern Bros .lith. 